\title{
Policy in focus: appeals for climate action, PHAC president steps down, FDA approves first e-cigarette
}

- Cite as: CMAJ 2021 November 1;193:E1671-2. doi: 10.1503/cmaj.1095966

Posted on cmajnews.com on October 14, 2021

$\mathrm{T}$ he World Health Organization (WHO) and more than 300 health care organizations urged governments to step up efforts to address climate change ahead of the United Nations Climate Change Conference in Glasgow, Scotland.

"Climate change is the single biggest health threat facing humanity," the WHO warned in a report calling for transformational action across all sectors. Climate change and air pollution go hand in hand. The organization previously estimated nearly a quarter of all deaths globally are linked to environmental risks from air pollution to chemical exposure.

"Bringing down air pollution to WHO guideline levels, for example, would reduce the total number of global deaths from air pollution by $80 \%$ while dramatically reducing the greenhouse gas emissions that fuel climate change. A shift to more nutritious, plant-based diets in line with WHO recommendations, as another example, could reduce global emissions significantly, ensure more resilient food systems, and avoid up to 5.1 million diet-related deaths a year by 2050," according to Dr. Maria Neira, WHO Director of Environment, Climate Change and Health.

The call to action coincided with a letter from organizations representing more than 45 million health care professionals around the world.

"Wherever we deliver care, in our hospitals, clinics and communities... we are already responding to the health harms caused by climate change," the letter stated. These harms include increases in food-borne, water-borne, and vectorborne diseases, injuries and deaths from extreme weather events, and the mental health toll of the climate crisis.

An estimated $85 \%$ of the world's population has been exposed to the human-induced impacts of climate change, according to a paper in Nature Climate Change. Using machine learning, researchers reviewed more than 100000 climate impact studies to produce an evidence map, which they compared with location-specific trends in surface temperature and precipitation.

They found that "attributable anthropogenic impacts may be occurring across $80 \%$ of the world's land area, where $85 \%$ of the population reside."

Health professionals have an important role to play in pushing for climate action, according to an editorial in The $B M J$. In addition to changing what they buy and eat and how they commute, clinicians can leverage their position as respected community members to inform public debate, lead efforts to reduce the health system's carbon footprint and influence their patients.

Meanwhile, British physicians are increasingly prescribing time in nature to support patients' mental health. Known as "green social prescribing," research links spending two hours in nature per week with consistently higher levels of health and well-being.

Last year, the United Kingdom's National Health Service invested $£ 5$ million in nature projects aimed at improv- ing mental health - from treep lanting to tending gardens. Now, there are more than 1000 "social prescribing" workers embedded in primary care practices in the UK helping doctors link patients to nature activities, as well as arts, heritage and exercise groups.

\section{In other health policy news:}

- Associate deputy minister of health Harpreet Kochhar replaced Iain Stewart as president of the Public Health Agency of Canada (PHAC) as part of a shuffle of senior public servants. Stewart led the agency through much of the COVID-19 pandemic and became embroiled in controversy earlier this year when he refused to provide members of Parliament with unredacted documents on the firings of two scientists from Canada's highest-security laboratory. During his tenure as president, PHAC also faced questions about its political independence and an ongoing dispute over the role of Major General Dany Fortin as head of Canada's vaccine task force. Stewart will return to his former role as president of the National Research Council of Canada. Incoming PHAC president Kochhar is a veterinarian by training and has served as Canada's chief veterinary officer and as associate vicepresident of operations at the Canadian Food Inspection Agency.

- The United States Food and Drug Administration for the first time authorized the sale of an e-cigarette in a move that experts say may be a 
turning point in public health debate over vaping. The FDA greenlit the Vuse Solo e-cigarette and tobaccoflavoured cartridges based on evidence provided by the manufacturer that the device helped smokers quit or reduce smoking. Previously, the regulator rejected or delayed similar applications for more than a million vaping products because of their potential appeal to teens.

Greg Basky, Saskatoon, Sask.

Content licence: This is an Open Access article distributed in accordance with the terms of the Creative Commons Attribution (CC BY-NCND 4.0) licence, which permits use, distribution and reproduction in any medium, provided that the original publication is properly cited, the use is noncommercial (i.e., research or educational use), and no modifications or adaptations are made. See: https:// creativecommons.org/licenses/by-nc-nd/4.0/ 